\title{
PERCEPÇÕES DE ADOLESCENTES ACERCA DA ESCOLA: RELAÇÕES ENTRE AS PROPOSTAS DAS POLÍTICAS PÚBLICAS PARA O ENSINO PROFISSIONALIZANTE E PERSPECTIVAS DE ESTUDANTES \\ http://dx.doi.org/10.5902/2176217114353
}

\author{
Naiana Dapieve Patias \\ Universidade Federal do Rio Grande do Sul, Brasil.
}

\begin{abstract}
Resumo
Esse estudo teve como objetivo analisar, por meio da percepção de um grupo de adolescentes, quais as relações e significados atribuídos às propostas das políticas públicas relacionadas à escola profissionalizante. Foram entrevistados adolescentes que cursavam o último semestre de dois cursos técnicos integrados ao ensino médio de uma escola da cidade de Santa Maria, RS. Além de entrevistas individuais foi aplicado um questionário sóciodemográfico, com vistas a traçar um breve perfil dos estudantes. Para análise das entrevistas foram utilizadas análises de conteúdo. No geral, foi possível perceber que as expectativas dos estudantes em relação à escola são variáveis e que a experiência de escolarização tem diferentes significados para cada um deles.

Palavras-chave: adolescência, escola, políticas públicas, ensino profissionalizante.
\end{abstract}

\section{PERCEPTIONS OF ADOLESCENTS ABOUT SCHOOL: RELATIONS BETWEEN PROPOSALS PUBLIC POLICY FOR THE EDUCATION PROFESSIONAL AND PERSPECTIVES OF STUDENTS}

\begin{abstract}
This study aimed to analyze, through the perception by a group of adolescents, what the relationships and meanings attributed to proposals of public policies related professional school. Adolescents who were in the last semester of the two integrated high school in a school in the city of Santa Maria, RS technical courses were interviewed. Addition to individual interviews a sociodemographic questionnaire with a view to trace a brief profile of the students was applied. Content analysis were used to analyze the interviews. Overall, was possible to perceive that students' expectations towards school are variable and that the experience of schooling has different meanings for each. Key-words: adolescence, school, public policy, professional education.
\end{abstract}




\section{Introdução}

escolarização é um processo que está integrado ao conceito de adolescência.
Peralva (1997) e Pereira (2007) destacam que a partir do momento em que
crianças e adolescentes passaram a conviver na instituição encarregada para prepará-los para a vida adulta, a escola, é que emergiu o conceito de adolescência.

Com o tempo, a instituição escolar generalizou-se e foi estendida, pela obrigatoriedade da frequência decretada pelos estados nacionais, para a quase totalidade da população. Assim, a partir do século 19 percebe-se uma progressiva universalização da frequência à instituição escolar que, paulatinamente, foi apropriada pelos Estados e tornada objeto de políticas sociais.

Nesse sentido, a preocupação principal desse trabalho foi procurar perceber quais relações e significados são atribuídos por um grupo de adolescentes às propostas das políticas públicas relacionadas ao ensino profissionalizante no Brasil ou, em outras palavras, em que medida políticas governamentais, que estruturam formas de pensar, organizam e disciplinam o funcionamento do ensino profissionalizante, se relacionam com supostas expectativas de adolescentes que frequentam a instituição escolar.

\section{Políticas governamentais e ensino profissionalizante}

As políticas governamentais para a escolarização têm uma forte expressão na legislação. Na Lei de Diretrizes de Bases, por exemplo, ressalta-se que "a educação básica tem por finalidades desenvolver o educando, assegurar-Ihe a formação comum indispensável para o exercício da cidadania e fornecer-Ihe meios para progredir no trabalho e em estudos posteriores" (art. $2^{\circ}$ ).

Ao ensino médio atribuí-se as seguintes finalidades: consolidação e aprofundamento dos conhecimentos abordados no ensino fundamental, de forma que possibilitem o prosseguimento de estudos; a preparação básica para o trabalho e a cidadania; aprendizagem contínua, de modo que as pessoas possam ser capazes de se adaptar com flexibilidade a novas condições de ocupação ou aperfeiçoamento posteriores; o aprimoramento do estudante como pessoa humana, incluindo a formação ética e o desenvolvimento da autonomia intelectual e do pensamento crítico; a compreensão dos fundamentos científicos e tecnológicos dos processos produtivos, relacionando a teoria com a prática, no ensino de cada disciplina (MEC, 2000).

Em termos bem gerais, pode-se afirmar que ao ensino médio, enquanto etapa da escolarização básica, caberia desenvolver nas pessoas maior capacidade de intervenção no mercado de trabalho, bem como ampliar o capital cultural necessário ao exercício da vida social. Nesse contexto, comparecem os referenciais curriculares nacionais da educação profissional de nível técnico. Esses referenciais curriculares oferecem informações e indicações adicionais para a elaboração de planos de cursos nas diferentes áreas profissionais. Neles estão incluídas a caracterização dos processos de produção, a identificação de funções e subfunções neles distinguidas, competências, habilidades e bases tecnológicas nelas envolvidas ou para elas necessárias.

Por meio dos referenciais curriculares faz-se circular discursos que estruturam formas de operacionalização do ensino profissionalizante. Nesse âmbito, destaca-se o conceito de competências como elemento orientador da dinâmica curricular. As competências seriam 
ações e operações mentais [que] articulam os conhecimentos (o saber, as informações articuladas operatória-mente), as habilidades (psicomotoras, ou seja, o saber fazer elaborado cognitivamente e socioafetivamente) e os valores, as atitudes (o saber ser, as predisposições para decisões e ações, construídas a partir de referenciais estéticos, políticos e éticos) constituídos de forma articulada e mobilizados em realizações profissionais com padrões de qualidade requeridos, normal ou distintivamente, das produções de uma área profissional. Em síntese, a realização competente tem nela agregados saberes cognitivos, psicomotores e socioafetivos. A competência caracteriza-se, essencialmente, pela condição de alocar esses saberes, como recursos ou insumos, através de análises, sínteses, inferências, generalizações, analogias, associações, transferências, ou seja, de esquemas mentais adaptados e flexíveis, em ações próprias de um contexto profissional específico, gerando desempenhos eficientes e eficazes. (MEC, 2000, p. 10)

Nesse contexto, o currículo deve ser articulado com o meio, concebido de forma a promover aprendizagens profissionais significativas, pois, supostamente "a nova educação profissional desloca o foco do trabalho educacional do ensinar para o aprender, do que vai ser ensinado para o que é preciso aprender no mundo contemporâneo e futuro" (MEC, 2000, p. 10).

Assim, por meio desse estudo, que se assenta, principalmente, em perspectivas oriundas da Psicologia, buscou-se conhecer as percepções de um grupo de estudantes de uma escola que oferta cursos profissionalizantes na cidade de Santa Maria, RS, e quais as possíveis relações que as perspectivas, expectativas, desejos de adolescentes mantém com que é dito e escrito no âmbito das políticas governamentais. Esse estudo pode possuir relevância para a gestão escolar, na medida em que aponta indícios que permitem entender os modos pelos quais as políticas públicas são implantadas e se há relações dessas com as supostas expectativas formativas de adolescentes.

\section{Método}

O trabalho caracterizou-se como um estudo de caso. Conforme Yin (2005), essa metodologia se refere ao estudo detalhado de um objeto de estudo. O estudo de caso é particularista, descritivo e indutivo e o interesse centra-se na indagação de um fenômeno, população ou uma condição geral. Nesse estudo centrou-se a atenção nas percepções de adolescentes acerca da freqüência a um curso técnico integrado ao ensino médio.

Participaram do trabalho seis estudantes, três do gênero masculino e três do gênero feminino, com idade entre 16 e 19 anos, que cursavam o terceiro ano de dois cursos técnicos integrado ao ensino médio de uma escola da cidade de Santa Maria, RS. O número de participantes foi definido a posteriori, seguindo o critério de saturação.

Para a coleta dos dados foram utilizados dois instrumentos: uma ficha de dados sócio-demográficos, para investigar aspectos individuais e familiares, e uma entrevista individual semiestruturada, com questões relativas às percepções acerca da escola profissional. As entrevistas foram gravadas e transcritas na íntegra.

A escolha das participantes foi realizada por conveniência. Inicialmente entrou-se em contato com a instituição para explicar os objetivos e procedimentos do estudo, bem como para verificar a disponibilidade de colaboração com o estudo. Após o aceite da instituição o projeto foi submetido ao Comitê de Ética em Pesquisa da Universidade Federal 
de Santa Maria, onde foi aprovado e registrado sob o número Caae 0299.0.243.000-11.

Após aprovação do projeto pelo comitê, entrou-se em contato com os estudantes que se encaixavam no perfil do estudo. Os mesmos foram convidados, informados dos objetivos e procedimentos do estudo. Os que aceitaram participar da pesquisa assinaram o termo de consentimento livre e esclarecido. No caso dos estudantes menores de 18 anos, o termo foi assinado pelo responsável legal. Na sequência, foram agendados encontros para a realização das entrevistas, em local e horário cedidos pela escola.

Como técnica de análise dos dados foi utilizada a análise de conteúdo, conforme a proposta de Minayo (1994). Segundo a autora, essa técnica refere-se a um procedimento que visa a examinar a comunicação com o intuito de obter indicadores que permitam a inferência de conhecimentos relativos às condições de produção das mensagens. Assim, a técnica de análise de conteúdo dirige-se à descrição objetiva, sistemática e quantitativa do conteúdo manifesto das comunicações para, após, interpretá-los.

Minayo (1994) aponta três etapas para a realização da análise de conteúdo: busca e ordenamento dos dados, procedimento pelo qual se mapeiam todos os dados obtidos na etapa da pesquisa de campo. Esta etapa envolve a transcrição das entrevistas, a organização dos relatos dos dados do diário de campo e a releitura do material. Em seguida fazse a classificação, que inicialmente consiste em uma leitura exaustiva e repetida dos textos com vistas a estabelecer interrogações que identifiquem idéias centrais do tema em foco. Com base nos dados que se sobressaem, elaboram-se as categorias específicas. Por último, a análise final, momento no qual se procura estabelecer articulações entre os dados e os referenciais teóricos, para responder à questão norteadora da pesquisa e seus objetivos.

\section{Resultados e discussão}

Os resultados desse estudo foram estruturados em duas categorias: 1) perfil dos adolescentes, que revela como se caracteriza o público investigado e 2) percepções sobre a escola técnica integrada ao ensino médio. Essa categoria foi estratificada em três subcategorias, a saber: 2.1) o que esperava da escola, 2.2) o que a escola proporcionou e 2.3) planos futuros.

\section{1) Perfil dos adolescentes}

Dos seis estudantes entrevistados, nenhum possui vínculo empregatício e apenas um possui experiência em trabalho com os pais, em uma papelaria. Cinco possuem renda familiar acima de mil reais e a escolarização dos pais varia entre ensino médio completo e ensino superior completo.

Tabela 1- Perfil geral dos entrevistados.

\begin{tabular}{|l|l|l|l|l|l|}
\hline $\begin{array}{c}\text { Nome } \\
\text { fictício }\end{array}$ & Idade & $\begin{array}{c}\text { Curso técni- } \\
\text { co }\end{array}$ & Renda familiar & $\begin{array}{l}\text { Escolaridade da } \\
\text { mãe }\end{array}$ & $\begin{array}{c}\text { Escolaridade do } \\
\text { pai }\end{array}$ \\
\hline Tina & 18 & Eletrotécnica & $\begin{array}{l}\text { Menos de } \mathrm{R} \$ \\
1.000,00\end{array}$ & $\begin{array}{l}\text { Ensino médio } \\
\text { completo }\end{array}$ & $\begin{array}{l}\text { Ensino médio } \\
\text { completo }\end{array}$ \\
\hline Rui & 18 & Eletrotécnica & $\begin{array}{l}\text { Mais de } \mathrm{R} \$ \\
2.000,00\end{array}$ & $\begin{array}{l}\text { Ensino superior } \\
\text { completo }\end{array}$ & $\begin{array}{l}\text { Ensino superior } \\
\text { completo }\end{array}$ \\
\hline
\end{tabular}




\begin{tabular}{|l|l|l|l|l|l|}
\hline Ana & 17 & Eletrotécnica & $\begin{array}{l}\text { Mais de } \mathrm{R} \$ \\
2.000,00\end{array}$ & $\begin{array}{l}\text { Ensino superior } \\
\text { completo com } \\
\text { Pós-graduação }\end{array}$ & $\begin{array}{l}\text { Ensino superior } \\
\text { completo }\end{array}$ \\
\hline Júlia & 17 & Eletrotécnica & $\begin{array}{l}\text { Mais de } \mathrm{R} \$ \\
1.000,00\end{array}$ & $\begin{array}{l}\text { Ensino funda- } \\
\text { mental completo }\end{array}$ & $\begin{array}{l}\text { Ensino funda- } \\
\text { mental completo }\end{array}$ \\
\hline Pedro & 17 & Mecânica & $\begin{array}{l}\text { Mais de } \mathrm{R} \$ \\
1.000,00\end{array}$ & $\begin{array}{l}\text { Ensino superior } \\
\text { completo }\end{array}$ & $\begin{array}{l}\text { Ensino médio } \\
\text { completo }\end{array}$ \\
\hline Gustavo & 19 & Mecânica & $\begin{array}{l}\text { Mais de } \mathrm{R} \$ \\
1.000,00\end{array}$ & $\begin{array}{l}\text { Ensino superior } \\
\text { completo com } \\
\text { pós-graduação }\end{array}$ & $\begin{array}{l}\text { Ensino funda- } \\
\text { mental completo }\end{array}$ \\
& & & & & \\
\end{tabular}

2) Percepções sobre a escola técnica integrada ao ensino médio

2.1) O que esperava da escola

No geral, os entrevistados disseram esperar que a escola se constituísse num lugar que, além da decisão da escolha profissional, oferecesse um ensino diferenciado. Esse ensino diferenciado envolve duas dimensões: a) formação de ensino médio com vistas ao ingresso no ensino superior; b) ensino profissionalizante que remete para a empregabilidade: "A minha expectativa era a de encontrar uma profissão aqui dentro" (Tina, 18 anos); "Cria-se uma expectativa de que, ao frequentar a escola, a gente vai conseguir mais facilmente entrar no mercado de trabalho" (Gustavo, 19 anos).

Essas mesmas expectativas são ressaltadas em trabalho realizado no Paraná, por Garcia (2009). Essa autora entrevistou 30 estudantes de um curso de ensino médio integrado ao técnico e percebeu que os estudantes esperavam que a escola permitisse, de maneira mais facilitada, o acesso ao mercado do trabalho e a continuidade da escolarização, com o ingresso no ensino superior. Além disso, esperavam um ensino qualificado, um algo a mais do que apenas o ensino médio.

Leão, Dayrell e Reis (2011) entrevistaram 245 jovens estudantes de ensino médio do Estado do Pará, com o objetivo de analisar projetos de vida e as escolas públicas de ensino médio. Os autores constataram que os jovens esperavam que a escola preparasse para o mercado de trabalho e para exames - vestibular, Enem. Perspectivas similares foram percebidas nesse estudo, principalmente nos depoimentos de Rui e Ana: "Eu esperava uma coisa bem melhor [...] mais voltado ao vestibular, ao Peies e isso eu não vi. [...] Eu esperava conseguir um bom trabalho aqui" (Rui, 18 anos); "Eu esperava um ensino diferenciado das outras escolas públicas. Além do ensino médio, eu procurava um diferencial para o meu currículo, que seria o técnico" (Ana, 17 anos).

De acordo com Pereira e De Souza (2003), parece que a maior dificuldade do ensino médio está em sua identidade e finalidade, pois persiste sua dupla função: preparar para a continuidade dos estudos e, ao mesmo tempo, para o mundo do trabalho. Essa dupla função está presente na manifestação dos estudantes quando alguns afirmam que esperava da escola mais conteúdos que preparassem para o vestibular ou, ao contrário, quando esperavam mais prática, preparando para o trabalho. Isto é, a escola, mesmo integrada, parece não contemplar expectativas dos estudantes. 
Ou seja, enquanto os referenciais curriculares nacionais para a educação profissional de nível técnico (2000) propõem que a escola profissionalizante seja "uma modalidade própria da educação que deve estar articulada coma educação básica e, no caso do nível técnico, ser complementar ao ensino médio" (p. 12), os estudantes esperam profissionalizarem-se e estudar aqueles conteúdos requeridos para o ingresso no ensino superior: "Obtive conhecimentos mais na parte da eletrotécnica, no resto das matérias não foi um grande conhecimento que eu obtive. Por isso estou fazendo cursinho" (Rui, 18 anos); "É no cursinho que eu vou recuperar as matérias que eu não consegui pegar direito aqui no colégio" (Gustavo, 19 anos).

A manifestação de Gustavo remete à necessidade de acúmulo de conteúdos e matérias, concepção que parece não ser a do currículo por competência. De fato, segundo Carvalho e Martins (2013), a pedagogia das competências se contrapõe aos métodos tradicionais de ensino baseados no processo de acúmulo de conhecimentos. Assim, a noção de competências designa a capacidade de mobilizar diversos recursos cognitivos para enfrentar situações. Dessa forma, as competências são uma forma de saber fazer e não uma forma de conhecimento.

Os aspectos ressaltados pelos entrevistados também foram encontrados na pesquisa de Garcia (2009) que revela, pelos depoimentos de estudantes e gestores, que uma das dificuldades do ensino técnico integrado ao ensino médio é a de integração desses dois ensinos: ora se prioriza o ensino teórico, ora se prioriza o ensino prático. Os gestores e os professores entrevistados afirmam que essas dificuldades advêm, principalmente, da falta de preparação e capacitação dos professores.

\section{2) O que a escola proporcionou}

Os entrevistados destacaram, dentre suas expectativas, que esperavam encontrar um ensino de qualidade que fornecesse conhecimentos teóricos, tanto para o vestibular, quanto para o trabalho, e que também pudessem ajudar na escolha da profissão: "Dá para dizer que eles te dão a base pra ti seguir no mercado de trabalho" (Tina, 18 anos). Por outro lado, a manifestação de Rui parece dizer o oposto: "[não aprendi muitos] conhecimentos práticos [...]. No terceiro ano eu esperava ter muita aula prática [mas] acabamos tendo só em uma matéria" (Rui, 18 anos). Já Gustavo menciona a falta de conhecimento teórico, voltado para o vestibular: "Eu acho que poderia preparar, mas não tá preparando para o vestibular. [...] Eu esperava mais, esperava que fosse mais puxado o ensino aqui" (Gustavo, 19 anos):

Entrevistadora: E a escola não te proporcionou aquilo que tu esperavas? Sim me proporcionou. Os professores são de alto nível, a estrutura do colégio é muito boa, tem ar condicionado. Eu aprendi bastante no colégio [...]. Entrevistadora: e tu te sentes preparada para o mercado de trabalho? Preparada totalmente não. Eu tenho a impressão de que eu não sei nada. Mas dizem que é normal isso". (Julia, 17 anos); "Entrevistadora: A escola te proporcionou o que é necessário para entrar no mercado de trabalho? Acredito que sim, apesar de eu achar que falta um pouco de incentivo da escola dizer, mostrar como é a empresa desde o começo, por que ela deixa só para falar no terceiro ano". (Pedro, 17 anos)

Essa dualidade e fragmentação nas manifestações dos entrevistados são representativas do ensino médio integrado à educação profissional. Segundo Chiavatta e Ramos 
(2011), a criação do ensino médio integrado ao ensino técnico foi uma necessidade social e histórica, condição, segundo os autores, necessária para a superação da dualidade de classes. No entanto, os mesmos autores afirmam que permanecem contradições na existência de diferentes programas.

Dessa forma, como percebido nas manifestações dos entrevistados, há um predomínio de duas visões ou práticas dicotômicas: de um lado, uma visão sobre o ensino médio profissionalizante como compensatória e, de outro, a defesa de um ensino médio propedêutico, sendo a profissionalização um processo específico e independente. Assim, permanece um visão fragmentada entre esses dois ensinos, separando-se a educação geral, destinada à preparação para os estudos superiores, e a preparação imediata para o mercado de trabalho (Chiavatta; Ramos, 2011).

Segundo Ramos (2011) a formação básica e profissional acontecem, no caso do ensino médio integrado, em uma mesma instituição de ensino, num mesmo curso e com currículos e matrículas únicas. Além disso, pressupõe a possibilidade de um currículo integrado e a superação dualidades. Por outro lado, a autora afirma que se deve problematizar sobre a ênfase e aspirações dos estudantes, já que embora a escola seja uma instituição que tem por finalidade a socialização do saber sistematiza, ela somente o fará, se for o interesse dos alunos.

De fato, esse é um aspecto importante, pois, de acordo com a legislação em vigor, a escolarização é dever de todos. No entanto, a permanência nela dependerá de vários aspectos. A respeito disso, Fanfani (2000), afirma que a escola precisa fazer sentido aos adolescentes, já que muitos deles se questionam a respeito do porque ir à escola. De fato, para que os estudantes permaneçam na escola, esses devem ter razões para isso.

Fanfini (2000) revela algumas respostas possíveis que podem servir de estímulo para que os adolescentes permaneçam na escola: 1) obrigação como sentido: frequenta o ensino médio pela obrigatoriedade estabelecida pela legislação; 2) razão instrumental: lógica do adiamento de benefícios - amanhã serei alguém na vida se hoje estudar; 3) amor ao conhecimento: entrega ao campo do saber. $O$ autor afirma que essas respostas são ideais, já que para muitos jovens, principalmente de camadas populares, é difícil se assentar em alguma delas, já que essas camadas sociais possuem urgências e pressões de sobrevivência que os impossibilita projetar-se no futuro.

Além de aspectos sócioeconômicos envolvidos no aspecto do sentido da escola, questões individuais da adolescência e da cultura juvenil influenciam nos sentidos conferidos à escolarização pelos jovens (Aberastury e Knobel, 1981; Fanfini, 2000). Em termos individuais, há uma dificuldade do jovem projetar-se no futuro. Então, os jovens tendem a pensar apenas no presente, não conseguindo interligar aspectos do comportamento atual com conseqüências futuras.

Já no que diz respeito às culturas juvenis, Fanfani (2000) ressalta que os jovens possuem uma cultura que lhes é própria - características objetivas e subjetivas, expectativas, preferências, atitudes e comportamentos - e que pode gerar contradições com a oferta das escolas que, em alguns casos, não considera demandas e expectativas dos adolescentes. A respeito disso, Rocha (2002), afirma que o que tem acontecido em termos de escolarização dos jovens é um desencontro entre as expectativas e esperanças construídas no seio familiar dos jovens em torno dos valores da escola e aspirações juvenis - ascensão social, melhoria das condições de vida - e a experiência 
cotidiana das escolas. Esse desencontro pode gerar desinteresse, indisciplina e violência, na medida em que a trajetória da escolarização gera, muitas vezes, o insucesso e a exclusão.

Sobre o interesse dos estudantes, Ramos (2011) lembra que a atratividade do ensino médio integrado adviria da oportunidade de obter logo uma profissão. De fato, parece que para alguns dos entrevistados essa foi a motivação na busca pelo ensino integrado. No entanto, outros possuíam outras perspectivas que parecem não ter sido satisfeitas.

\section{3) Planos futuros}

Todos os entrevistados relataram que têm como plano concluir o ensino médio e buscar ingresso no ensino superior. Revelam, ainda, que pretendem concluir o ensino médio com a realização de um bom estágio o que, para eles, significa quase uma garantia de emprego: "Eu pretendo [...] fazer um estágio bom, numa empresa boa [...] depois [cursar] engenharia elétrica [...]. Eu quero mais é dinheiro" (Rui, 18 anos); "Eu penso em conseguir um emprego bom, um estágio bom, ter um currículo bom, para conseguir um emprego bom, para ganhar um bom dinheiro" (Julia, 17 anos).

Nota-se, portanto, que as expectativas dos estudantes em relação à escola são variáveis e que a experiência de escolarização tem diferentes significados para cada um. Em outras palavras, há um conjunto bastante amplo de elementos que atravessam o que prescrevem as políticas para a escolarização, propostas no âmbito governamental e formuladas a partir de discursos de circulação internacional, as práticas ou modos de operacionalização dessas políticas por cada uma das instituições escolares e os diferentes desejos, expectativas e usos que os estudantes fazem da freqüência à escola.

\section{Considerações finais}

Por fim, cabe destacar que a frequência à escola, em especial por jovens, é atravessada por uma multiplicidade de fatores os quais, em alguma medida, não são capturados pelas políticas governamentais que visam a promover a escolarização e a profissionalização. Muitas vezes, estudantes apresentam motivações e desejos que não são aqueles formulados no âmbito das políticas governamentais. Nesse sentido, se, por um lado, propõe-se que escola profissionalizante seja uma modalidade própria da educação que deve estar articulada com a escola básica, por outro, ou complementar a isso, os entrevistados apontaram que esperam se profissionalizar, com vistas ao ingresso imediato do mundo do trabalho e estudar aqueles conteúdos requeridos para o ingresso no ensino superior.

É nesse contexto, às vezes dúbio, que acontecem variadas formas de interação entre professores, estudantes, dirigentes de instituições escolares, empresas, mundo do trabalho, aspirações, desejos imediatos, discursos, valor social atribuído à escola por diferentes grupos sociais, itinerários pessoais, aspectos econômicos. Por isso, talvez convenha observar e estudar essas dimensões no âmbito da administração de instituições escolares vinculadas à profissionalização, uma vez que as formas de apropriação dos discursos feitos circularem pelos documentos produzidos no âmbito governamental são tão variáveis quanto às perspectivas de cada estudante ou jovem: 
Estudos sobre a formação integrada evidenciam as dificuldades, mas não a impossibilidade de sua implantação, desde que apoiados por um projeto firme e coerente para sua realização, que supõe: a superação da mentalidade conservadora dos padrões pedagógicos vigentes, assim como de posições políticas adversas ao discurso da formação integrada e da educação emancipatória que tenha base na crítica à sociedade de mercado; gestão e participação democrática nas instituições educacionais; estudo e qualificação conceitual e prática dos professores; envolvimento do quadro docente permanente e transformação dos vínculos precários de trabalho para proporcionar a todos os professores condições materiais (instalações, laboratórios etc.) e condições dignas de trabalho, salariais, de carreira e compromisso com as instituições. (Chiavatta; Ramos, 2011, p. 36)

Cabe ressaltar que esse estudo foi realizado com alguns estudantes de dois cursos de ensino médio integrado ao ensino profissional, de uma escola de Santa Maria, RS. Essas são as perspectivas e planos desses adolescentes e que não podem ser generalizadas. Sugere-se que outros trabalhos possam contemplar um número maior de estudantes, de várias escolas, a fim de buscar um aprofundamento dessas questões de modo que as perspectivas dos estudantes possam ser consideradas como subsídios na implantação de políticas públicas sobre a educação dos adolescentes.

\section{Referências}

ABERASTURY, Arminda; KNOBEL, Maurício. Adolescência normal: um enfoque psicanalítico. Porto Alegre: Artes Médicas, 1981.

CARVALHO, Saulo; MARTINS, Lígia. A escola pública e as competências para o mercado: realidade e mitos. Revista Semestral da Associação Brasileira de Psicologia Escolar e Educacional, v. 17, n. 1, 2013, p. 141-149.

CHIAVATTA, Maria; RAMOS, Marise. Ensino médio e educação profissional no Brasil: Dualidade e fragmentação. Revista Retratos da Escola, v. 5, n. 8, 2011, p. 27-41.

FANFANI, Emilio Tenti. Culturas jovens e cultura escolar. In: SEMINÁRIO ESCOLA JOVEM: UM NOVO OLHAR SOBRE O ENSINO MÉDIO, 2000, Brasília. Anais ... Brasília: MEC, 2000. Disponível em: http://www.mec.gov.br/semtec/ensmed/ artigosensaios.shtm. Acesso em 11 out., 2011.

GARCIA, Sandra Regina. A educação profissional integrada ao ensino médio no Paraná: avanços e desafios. Curitiba: UFPR, 2009, 147f. Tese (doutorado em Educação). Universidade Federal do Paraná, Programa de Pós-Graduação em Educação.

YIN, Robert. Estudo de caso: planejamento e método. Porto Alegre: Bookman, 2005.

Lei de Diretrizes e Bases da Educação Nacional. Brasília: Imprensa Oficial, 1996.

LEÃO, Geraldo; DAYRELL, Juarez; REIS, Juliana. Jovens olhares sobre a escola do ensino médio. Cadernos Cedes, v. 31, n. 84, 2011, p. 253-273.

MINAYO, Maria Cecília de Souza. O desafio do conhecimento: pesquisa qualitativa em saúde. São Paulo: Hucitec-Abrasco, 1994.

MINISTÉRIO DA EDUCAÇÃO. Educação profissional: referenciais curriculares nacionais da educação profissional de nível técnico. Brasília: MEC, 2000.

MINISTÉRIO DA EDUCAÇÃO. Educação profissional técnica de nível médio integrada ao ensino médio: documento base. Brasília: MEC, 2007. 
PERALVA, Angelina. O jovem como modelo cultural. Revista Brasileira de educação, n. 5, v. 6, 1997, p. 13-27.

PEREIRA, Alexandre Barbosa. Aprendendo a ser jovem: a escola como um espaço de sociabilidade juvenil. In: CONGRESSO BRASILEIRO DE SOCIOLOGIA, 13, 2007, Recife. Anais ... Recife: SBS, 2007, p. 1-15.

PEREIRA, Lúcia. Ensino médio: à procura de identidade. Contexto e Educação, v. 18, n. 70, 2003, p. 63-91.

RAMOS, Marise. O currículo para o ensino médio em suas diferentes modalidades: Concepções, propostas e problemas. Educação e Sociedade, v. 32, n. 116, 2011, p. 771-788.

ROCHA, Marisa. Contexto do adolescente. In: KOLLER, Sílvia Helena (org). Adolescência \& Psicologia: concepções, práticas e reflexões críticas. Rio de Janeiro: Conselho Federal de Psicologia, 2002, p. 25-32.

Naiana Dapieve Patias é psicóloga, mestre em Psicologia e estudante do curso de doutorado em Psicologia na Universidade Federal do Rio Grande do Sul.

Endereço: Rua Ramiro Barcelos, 2600 - 90035-003 - Porto Alegre - RS - Brasil.

E-mail: naipatias@hotmail.com.

Recebido em 3 de maio de 2014.

Aceito em 10 de junho de 2014. 